Trinity University

Digital Commons @ Trinity

Communication Faculty Research

Communication Department

8-2018

\title{
Toward a Multi-Dimensional Model of Adolescent Romantic Parasocial Attachment
}

\section{Sarah E. Erickson}

Trinity University, serickso@trinity.edu

K. Harrison

Sonya Dal Cin

Follow this and additional works at: https://digitalcommons.trinity.edu/comm_faculty

Part of the Communication Commons

\section{Repository Citation}

Erickson, S. E., Harrison, K., \& Dal Cin, S. (2018). Toward a multi-dimensional model of adolescent romantic parasocial attachment. Communication Theory, 28(3), 376-399. doi: 10.1093/ct/qtx006

This Post-Print is brought to you for free and open access by the Communication Department at Digital Commons @ Trinity. It has been accepted for inclusion in Communication Faculty Research by an authorized administrator of Digital Commons@ @rinity. For more information, please contact jcostanz@trinity.edu. 


\begin{abstract}
Relationships with media figures — referred to as parasocial relationships — provide a means for adolescents to explore and define their romantic and sexual identities (Boon \& Lomore, 2001; Engle \& Kasser, 2005; Karniol, 2001). However, more often than not, adolescents' romantic attachments to media figures are ignored or dismissed as frivolous in the scholarly literature on youth development (Caughey, 1984; Jenkins, 1992; Willis, 1972). In this paper, we introduce a theoretical model of Adolescent Romantic Parasocial Attachment (ARPA), designed to facilitate a comprehensive, developmentally-based line of research that improves our understanding of the ways adolescents experience parasocial romance and the influence their experiences may have on their lives. Implications for the study of adolescent romantic development and future research directions are proposed.
\end{abstract}

Key words: sexual socialization, adolescence, parasocial relationships, romantic relationships, celebrity worship 
Toward a Multi-dimensional Model of Adolescent Romantic Parasocial Attachment

From Shakespeare's Romeo and Juliet to Twilight's Edward and Bella, the drama of early love has captivated audiences for centuries. Perhaps, this fascination stems from our own intense memories of the emotional rollercoaster of first love. Developmentally, early adolescent experiences with romance are serious, emotionally charged undertakings with consequential developmental implications. Early romantic experiences can shape long-term romantic relationship quality, relationship satisfaction, identity development, and overall well-being (Furman \& Shaffer, 2013; Meier \& Allen, 2009), and can also influence identity, changes in family and peer relationships, career planning, and developing sexuality (Collins, Welsh, \& Furman, 2009).

Given their centrality in human development, it is important to understand the full developmental range of romantic orientations and experiences in adolescence, from the earliest experiences with crushes to serious committed romantic relationships (B.B. Brown, 1999; Meieir \& Allen, 2009). However, current theoretical models begin with experiences of attachment to or crushes on peers, revealing the underlying assumption that early experiences of romance must occur in person and involve the potential for interaction (B.B. Brown, 1999). In fact, adolescents' earliest romantic experiences are often romantic attachments to distant figures such as celebrities and media figures (Karniol, 2001). These attachments provide a baseline level of knowledge and set expectations for young adolescents experiencing romantic feelings for the first time (Karniol, 2001; Miller \& Sroufe, 1999). In this paper, we develop the construct of Adolescent Romantic Parasocial Attachment (ARPA) as a theoretical model for better understanding the complexity and nuance of these romantic attachments to media figures and the role they play in adolescent psychosocial development. 
Relationships with fictional or celebrity characters are a normal and common part of the adolescent social world (Caughey, 1984; Giles, 2002; Horton \& Wohl, 1956). These relationships provide a means for adolescents to explore and define their romantic and sexual identities (Boon \& Lomore, 2001; Engle \& Kasser, 2005; Karniol, 2001). Initial evidence suggests that adolescent romantic attachments to media figures could influence a) interpretation of media (Cohen, 2002, 2003), b) development of relational scripts, schemas, and normative beliefs (Basil, 1996; Erickson \& Dal Cin, 2017), c) future partner preferences (Adams-Price \& Greene, 1990; Burnett \& Beto, 2000), d) relationship expectancies (Adams-Price \& Greene, 1990; Burnett \& Beto, 2000, Segrin \& Nabi, 2002), and ultimately, e) relational happiness and overall well-being (Erickson \& Dal Cin, 2017; Galliher, Rostosky, Welsh, \& Kawaguchi, 1999; Johnson, Kent \& Yale, 2012).

However, in the scholarly literature on youth development, adolescents' romantic attachments to media figures are sometimes ignored or dismissed as frivolous (Caughey, 1984; Jenkins, 1992; Willis, 1972). With the exception of work from scholars such as Henry Jenkins (1992) and Mark Duffett (2013), theoretical discussions that do focus on fan romantic attachment often emphasize extremes (Spitzberg \& Cupach, 2008) and fan violence (Caughey, 1984). We argue that the experiences of young adolescent fans have been under-theorized, under-studied, and over-pathologized (Jenson, 1992). As a result, communication scholars and psychologists have yet to fully consider the possible developmental role of parasocial romantic relationships with media figures for adolescents. Nor have we adequately considered the long-term influence of fan-figure relationships on sexual and romantic socialization. Theoretically-driven work, which addresses the experience of romantic attachment to media figures as a common, developmentally appropriate phenomenon that has implications for the socialization of 
adolescents into the worlds of sex and relationships, is necessary. We must approach the study of adolescent romantic attachment to media figures in a nuanced manner, accounting for the full complexity of these attachment experiences by integrating theory and empirical findings from the multiple literatures that have touched upon this issue.

In this paper, we introduce a model of Adolescent Romantic Parasocial Attachment (ARPA) designed to facilitate a comprehensive, developmentally-based line of research that improves our understanding of the ways adolescents experience parasocial romance and the influence their experiences may have on their lives. Adolescent Romantic Parasocial Attachment can be defined as perceived romantic relationships with media figures in adolescence, which (a) involve the investment of time, energy, and emotion on the part of the adolescent; (b) are mediated; and (c) involve some degree of idealization. We use the term "parasocial attachment" rather than parasocial relationship intentionally. Stever (2013) argues that, beyond parasocial relationships, parasocial attachments represent a specific phenomenon related to infant-caregiver and adult romantic attachments and should be incorporated into the literature on developmental attachment. In this paper, we deliberately use the term "parasocial attachments" to emphasize our developmental perspective.

As depicted in Figure 1, current theorizing around adolescent experiences with romantic parasocial attachment primarily comes from the fields of (1) Developmental Psychology, where the focus has been on adolescent romantic and sexual development; (2) Communication, where the focus has been on parasocial relationships; and (3) Clinical Psychology, where the focus has been the clinical significance of celebrity worship. We will briefly review the relevant research from each of these fields, discussing the points of intersection (where they exist) and 
highlighting gaps in the research, before explicating our theoretical model of Adolescent Romantic Parasocial Attachment and proposing a model-based research agenda. [INSERT FIGURE 1 ABOUT HERE]

\section{Developmental Psychology: Adolescent Romantic and Sexual Development}

Social and biological changes in early adolescence co-create a unique moment in development during which engagement with media and attachment to media figures become especially common and appealing. Biologically, young adolescents (ages 10-13) are developmentally disposed to seek out romantic experiences (Collins, Welsh, \& Furman, 2009). The hormonal and neurological changes occurring during adolescence are also associated with visible physical changes, which may affect the way a given adolescent understands their identity and how they are seen by the surrounding world (Feiring, 1999). Importantly, puberty in the United States is occurring about five years earlier than it did in the earlier half of the $20^{\text {th }}$ century, and as a result, adolescents are exploring romantic emotions and experiences at an earlier age, even if only through the responses of others to their physical appearance (Larson, Clore, \& Wood, 1999).

As these biological changes occur, children and adolescents are learning social norms and appropriate behaviors from the world around them. One of the most challenging aspects of adolescent socialization is initiation into the world of dating and romantic relationships (Shulman \& Seiffe-Krenke, 2001). Using information from early romantic interactions (both observed and experienced), adolescents must develop appropriate and accurate scripts, schemas, beliefs, and behaviors for romantic relationships (Furman \& Simon, 1999). Initial attraction to romantic partners and entry into the realm of romantic experience generally begins in the first half of middle school, around early $7^{\text {th }}$ grade (B.B. Brown, 1999). In a nationally representative sample 
of adolescents, $25 \%$ of 12 -year-olds reported having a "special romantic relationship" in the past 18 months, whereas by age 16 , over $50 \%$ of adolescents report experiencing a romantic relationship within the last 18 months (Carver, Joyner, \& Udry, 2003). These statistics demonstrate the increasing importance and centrality of romantic relationships across adolescent development and also the importance of early adolescence as a time of experimentation and learning prior to serious romantic engagement.

B.B. Brown (1999) defines four stages of adolescent romantic development: initiation, status, affection, and bonding. Early romantic experiences occur in two stages and focus on the development of individual identity and relationship context. The first stage, initiation, can involve crushes or early relationships, but the focus is on identity development and mastery of romantic knowledge and skills (B. B. Brown, 1999; Shulman \& Seiffe-Krenke, 2001). The second stage, status, revolves around status within the peer group. In this stage, adolescents work to determine who peers will accept as an appropriate partner and what behaviors, attitudes, and beliefs about romantic relationships are acceptable within the peer group (B.B. Brown, 1999). The final two stages of development, affection and bonding, focus more on the romantic relationship itself than the individual or the context; the final stage reflects a mature bonded romantic partnership. B. B. Brown's (1999) model assumes linear development and a fixed end point — stable, long-term romantic attachment. It is worth noting that a) such straightforward linear development is unlikely, and b) considering stable, long-term romantic attachment as an indicator of completed romantic development does not take into account those for whom this endpoint is either not desired or not achieved (Collins \& van Dulmen, 2006). Meier and Allen (2009) suggest that progression through these stages does generally follow a distinct and 
consistent pattern; however, this progression is not necessarily uniform or unidirectional (Meier \& Allen, 2009).

Early adolescents enter the initiation stage of B.B. Brown's model with very little experience in romantic relationships. Yet, young adolescents do have a sense of the norms and expectations of romantic relationships and experiences from various socializing agents including peers, parents, community, and media (Collins, Welsh, \& Furman, 2009; Ward, 2003). In the initiation stage (B.B. Brown, 1999), adolescents are novices at romance and usually begin to experience it by having crushes before initiating actual relationships (Furman \& Simon, 1999). These romantic experiences can range from fantasies to interpersonal interactions such as watching a romantic movie, having a crush, talking about possible romantic partners with friends, going on a date, and so on (Collins, Welsh, \& Furman, 2009).

\section{Media and Romantic Socialization}

Past scholarly work on sexual socialization indicates that young adults turn to media to establish norms about sex and relationships. Ninety-four percent of youth indicate that they seek information about romantic love from TV and movies (Ward, 2002). Media portrayals of sex and relationships influence adolescents' attitudes and beliefs (related to sex, gender, relationships, gender roles, and sexual agency), and also their behaviors (in particular safe sex practices and sexual initiation; see Ward, Erickson, Lippman, \& Giaccardi, 2016 for a review of media and sexual socialization literature).

Although many have rightly raised concerns about adverse media effects on adolescents (Kim, Sorsoli, Zylbergold, Schooler, \& Tolman, 2007; Kirsch \& Murnen, 2015; Ward, 2003), media can also be a source of empowering information and developmental opportunities. The 
media provide adolescents with a chance to see the world outside their communities and to experiment with identities unavailable to them in their immediate environment (Gray, 2009). Media exposure may also provide fodder for fantasies, a critical element of development (Miller \& Benson, 1999).

One way in which media act as socialization agents for adolescents is by providing a platform for the development of adolescent attachment to media figures. The combination of hyper-sociality and hyper-sensitivity to rejection that comes with puberty creates a fertile environment for celebrity attachment. Romantic attachment to celebrities can satisfy increasing interest in romance and sexuality while minimizing risk, conflict, and rejection—all major concerns in romantic relationships (Adam \& Sizemore, 2013; Fisher, 2006; Karniol, 2001). Relationships with media figures provide a safe space for the exploration of sexuality and identity for adolescents.

Ultimately, the combination of neurological development, hormonal changes, increasingly outwardly oriented social worlds, and sexual socialization creates an ideal environment for adolescents to engage with celebrity culture in a romantic manner. However, although research psychologists have examined the role of media in romantic and sexual development, few have explored viewer relationships with media figures as developmentally significant phenomena (Ward, 2002).

\section{Communication: Parasocial Relationships}

In the communications literature, viewer relationships with media figures are known as parasocial relationships. Originally theorized by Horton and Wohl (1956), researchers in psychiatry, parasocial relationships are defined as relationships with media figures that are functionally similar to relationships with real people. Parasocial relationships are unidirectional, 
mediated attachments involving viewers' cognitive, affective, and behavioral responses to a media figure (Giles, 2002; Klimmt, Hartmann \& Schramm, 2006). Beyond communication, parasocial relationships have been examined across academic disciplines with much of the prominent work coming out of social psychology (e.g. Adams-Price \& Green, 1990; Stever, 2009; 2013).

Initial work on parasocial relationships focused on audience members' admiration of and friend-like attachment to non-fictional media personalities such as newscasters. However, this work has been expanded to incorporate media figures of all types, from celebrities and nonfictional characters to fictional and even fantasy figures. Further, although the majority of researchers continue to focus on dominant forms of parasocial relationships (specifically acquaintance and friendship based), others have proposed differentiated types of parasocial interaction, including parasocial attachment, parasocial identification, admiration, and parasocial romantic love (Auter \& Palmgreen, 2000; Stever, 2013; Tukachinsky, 2010).

\section{Parasocial Romance}

Parasocial romantic relationships are characterized by perceived physical and emotional intimacy with a media figure (Tukachinsky, 2010). Parasocial romantic relationships involve the feeling of being in love with or having a strong crush on a media figure and are especially strong and ubiquitous in adolescents (Greene \& Adams-Price, 1990). These relationships are a frequent and important aspect of adolescent development, allowing adolescents to safely explore adulthood with minimal sexual, social, or emotional risk (Brown, Barton White, \& Nikopoulou, 1993; Engle \& Kasser, 2005; Karniol, 2001). In mediated social relationships, the audience member has complete control over the interaction and, without fear of rejection or social conflict, can break off or increase the intensity of the relationship at any point (Theran, Newberg, \& 
Gleason, 2010). In these relationships, adolescents are able to maximize the benefits of romantic relationships while minimizing the risks (Adam \& Sizemore, 2013).

Current research on parasocial love focuses on similarities between parasocial and reciprocal relationships but fails to take sufficient account of the mediated nature of these relationships or their developmental functionality. For example, Tukachinsky's (2010) Multiple PSR Scale includes a parasocial love measure. However, although this scale accounts for the experience of parasocial love, Tukachinsky focuses on the similarities between parasocial love and reciprocal romantic relationships. Our proposed model, while complementary, attends specifically to the developmental perspective and also places particular emphasis on the mediated nature of the parasocial (i.e. its unidirectionality).

\section{Parasocial Romantic Attachment}

Based on this need for attention to existing developmental literature, Stever (2013) suggests the term "parasocial attachments" should be incorporated into our understandings of parasocial theory as a third level fan-figure relationship beyond PSI and PSR. She suggests that the components of attachment, specifically the "secure base" and "safe haven" aspects of the attachment relationship, are equally applicable in the realm of the parasocial. We agree with Stever's (2013) argument and further suggest- that parasocial attachment theory be incorporated into the attachment literature in developmental psychology. Some research has already connected parasocial relationships to attachment theory (for example, see Cohen, 2004) but use of Stever's term, "parasocial attachments," is limited.

\section{Clinical Psychology: Celebrity Worship}

Whereas communication scholars' focus has tended to be on similarities between "real" and parasocial relationships, clinical psychologists' research on celebrity worship accounts for 
both developmental and media factors. Celebrity worship, also referred to as "having a crush" on a celebrity, is defined as "an unreciprocated attachment to another characterized by frequent occurrence of fantasies in which the personal qualities of the other are greatly enhanced or idealized" (Adams-Price \& Greene, 1990, p. 187). This definition immediately highlights the distance between the object of the crush (the celebrity) and the person with the crush (the viewer) and distinguishes their distanced relationship from reciprocated interpersonal relationships. Whereas parasocial relationship research focuses primarily on similarities to "real" relationships with little attention to developmental considerations, work on celebrity worship focuses extensively on the mediated nature of these experiences, and, in the sub-field of celebrity idolization, researchers specifically examine adolescent development and how developmental stages may influence idolization practices, choices, and experiences.

Celebrity worship is most commonly measured by assessing tendencies to worship a celebrity that involve emotional attachment, obsessive thoughts, and specific fan behaviors (McCutcheon, Lange \& Houran, 2002). Three levels of celebrity worship have been identified in this literature: entertainment-social, intense-personal, and borderline-pathological. The entertainment-social level of celebrity worship reflects engagement with celebrities solely for entertainment and does not involve emotional attachment. Intense-personal levels of celebrity worship include a strong attachment and imagined closeness to the celebrity figures, and involve the devotion of time, energy, and resources to fan practices. Borderline-pathological fans are those who take fanship to what researchers characterize as an obsessive level, and are likely to engage in more extreme fan behaviors such as "over-identification with the celebrity [and] compulsive behaviors" (McCutcheon et al., 2002, 67; Spitzberg \& Cupach, 2008).

Emerging from a clinical perspective, research in this area has primarily focused on 
diagnosing clinically addressable problems related to pathology in fans (often using adult samples; Stever, 2011). For example, McCutcheon, Ashe, Houran, and Maltby (2003) found a correlation between what they call "obsessional tendencies" (p. 311) among fans (scores at the intense-personal and borderline-pathological levels) and lower psychological wellbeing and educational attainment. However, their findings (which also include negative relations between celebrity worship and creative ability, spatial reasoning, and critical thinking) are correlational and cannot be used to support a causal argument. The same group of authors also found that celebrity worship was associated with lower levels of social complexity, less cognitive flexibility, and increased depressive symptoms (Maltby, McCutcheon, Ashe, \& Houran, 2001). This focus on the extremes of fandom serves to identify cases with clinical importance and diagnostic implications but, in doing so, minimizes the quotidian and ubiquitous nature of fan idolization in adolescent development and sets aside possible advantages of this fandom. Acknowledging the potential for both adaptive and adverse functions of fan parasocial relationships allows for the emergence of new and fruitful areas of research, with opportunities to better understand this phenomenon and its role in development.

In general, researchers in the area of celebrity worship conclude that the connections they have observed are generally negative and troubling (Stever, 2011). However, from the perspective of adolescent development and communications, celebrity worship (particularly at the "middle" intense-personal level, about which some psychologists have expressed concerns; Maltby et al., 2001) seems to reflect "normal" parasocial relationships for adolescents. Scholars examining parasocial relationships argue that these types of relationships to media figures are not pathological or inherently troubling at all and are, in fact, a normal consequence of engagement with media (Giles, 2002). Adolescents may turn to celebrity worship as a way to sublimate 
romantic and sexual yearnings toward peers in their daily life (Karniol, 2001). Idealizing the celebrity object is particularly important to these discussions of the idolization process. Fans can project idealized qualities onto the celebrity object to fit their own needs and desires (Fraser \& Brown, 2002). Given the heightened emotional states of adolescence, intense-personal attachments to celebrities may be more intense and more personal in this audience than they are among adults (Karniol, 2001). Additional empirical and theoretical work is needed to clarify the magnitude of adolescent romantic attachment to celebrities and to address how it might compare to such attachments in childhood and adulthood.

\section{Open Questions and Concerns}

Each of these three bodies of literature examines some form of adolescent romantic development and the role of media and parasocial relationships in that development. Developmental psychologists provide models of the stages of adolescent romantic development and the social and biological factors influencing this development (B.B. Brown, 1999; Furman \& Shaffer, 2003). However, many psychologists address the media with which adolescents engage as an aside rather than as a central socializing agent and rarely examine variations in media engagement. In contrast, communication researchers examine parasocial relationships but focus mainly on adults or young children and the extent to which these parasocial attachments align with interpersonal relationships. Explorations of adolescent parasocial relationships, particularly those of a romantic nature, are scarce. Finally, clinical research on celebrity worship has focused on the role of idolization in outcomes that are significant for therapeutic or psychiatric reasons. As a result, extensive attention has been paid to rare problematic outcomes, leaving experiences common to many adolescents either ignored or (perhaps unintentionally) pathologized. None of 
this work sufficiently examines adolescent romantic parasocial relationships as developmentally common, useful, or complex phenomena.

Despite a shared concern with adolescent celebrity attachment, there is limited dialogue between the literatures on adolescent development, parasocial interaction, and celebrity worship. A theoretical explication of ARPA must occur at the nexus of these three literatures: taking into account the powerful role of development in shaping these relationships, focusing on adolescence as an especially potent moment for romantic socialization and the development of parasocial romantic relationships, and limiting the pathologizing of fan experiences. The ARPA model, proposed below, follows this approach, providing the structure for more in-depth study of the causes, gratifications, and effects of parasocial romantic experiences for adolescents.

\section{The Adolescent Romantic Parasocial Attachment Model}

Adolescent romantic parasocial attachments are common and consequential developmental experiences. These relationships are motivated (Karniol, 2001), measurable (Tukachinsky, 2010), and have implications for adolescent development (Greene \& AdamsPrice, 1990). Through the ARPA model, we propose approaching these experiences from a phenomenological orientation that emphasizes their multi-dimensional nature. Previous literature on parasocial relationships identifies three components of these relationships: emotions, cognitions, and behaviors (Klimmt, Hartmann, \& Schramm, 2006). Building on this literature, we view ARPA as composed of four interrelated elements: emotions, cognitions, behaviors, and fantasies (Klimmt et al., 2006; Shulman \& Seiffge-Krenke, 2001). These elements are understood as non-orthogonal and highly correlated. However, we believe that each aspect of the model (see Figure 2) contributes unique theoretical insights into the ARPA experience, allowing for a deeper, more nuanced understanding of the phenomenon. 


\section{Components of Adolescent Romantic Parasocial Attachment}

Emotions. Emotions in parasocial relationships are generally related to connection with, or emotional responses to, media figures (Klimmt et al., 2006). Connections with media figures are activated in viewers' empathic reactions to these figures. Trait empathy, specifically empathic concern and perspective taking, increases the likelihood of transportation into a narrative and the salience of fan identity (Taylor, 2015). The adolescent imagines what that person might be feeling and shares the emotion with the media figure (Klimmt et al., 2006). For example, when a media figure loses a loved one, a young woman with a romantic parasocial attachment to that media figure may feel grief and sadness at the loss or at the perceived sadness of the star. This is not a conscious response. As in interpersonal relationships, fans feel empathy toward those with whom they perceive an emotional connection. Because the object of their affection is grief-stricken, so are they.

In addition to empathic reactions, emotional responses to media figures may involve selfgenerated emotions (Klimmt et al., 2006). These responses are about the individual and the relationship she imagines between herself and the media figure. For example, after a long week at school, an adolescent girl returning to her bedroom full of posters of her favorite media figure might feel excitement or joy at the idea of relaxing on her bed and fantasizing about this media figure.

\section{[FIGURE 2 ABOUT HERE]}

Cognitions. Cognitions associated with ARPAs involve attention allocation, making connections, and script and schema development (Klimmt et al., 2006). Adolescents spend a lot of time thinking about romantic partners (or potential romantic partners or crushes), and thoughts about romance and sex often precede sexual involvement in adolescent development (Furman \& 
Simon, 1999; Miller \& Srouffe, 1999). Allocation of attention to thoughts about a media figure is a defining feature of ARPA.

Beyond this allocation of cognitive attention to the media figure, ARPA are also characterized by cognitions around evaluative and critical thinking that help the adolescent make connections and draw conclusions (Klimmt et al., 2006). When thinking about their celebrity attachment, adolescents attempt to comprehend behaviors, ideas, and news about that celebrity; they make observations about the celebrity and attempt to anticipate future behaviors (e.g., Will he agree to be in that movie? Does he really love his girlfriend?). In their exploration of identity, adolescent fans also examine the ways that they are both similar to and different from their media attachments. These evaluations likely help them think through both their own identity and the identity of future partners. In ARPA, these types of cognitions can involve evaluating shared traits, considering ways to help or support the media figure, and attempting to learn as much as possible about the media figure. In the current media environment, social media may play a critical role in this process, providing a site for information gathering and potential interaction with media figures.

Finally, perhaps the most studied cognitions in adolescence are scripts and schemas. Through parasocial relationships, adolescents learn how to act, what to believe, and what to value. In the course of an ARPA experience, an adolescent has the opportunity to engage in experimentation with romantic scripts, to learn scripts and schema vicariously through the observation of the media figure, and to use discussions of the media figure with peers to gauge norms and ideals.

Behaviors. Another expression of Adolescent Romantic Parasocial Attachment (explored extensively in the fan studies literature) can be observed in adolescent behaviors. Steele and J. D. 
Brown's (1995) Media Practice Model highlights the interplay between media selection, behaviors, and identity development in adolescent audiences. Attachment theory emphasizes the importance of proximity seeking (Hazan \& Shaver, 1994) and many fan behaviors are undertaken with this goal in mind. For example, tweeting at a celebrity or having pictures of that celebrity in your room reflect a fan's desire for proximity to that celebrity.

Unfortunately, in much of the research, fan behaviors are often associated with pathology (Spitzberg \& Cupach, 2008). Moreover, they vary greatly across participants due to structural factors such as means, access, and mobility; therefore, behavior alone does not indicate degree of fanship. For example, waiting outside a TV studio to meet a Hollywood star or going to all of a certain musician's concerts might not be possible for an adolescent living with limited financial means or in a remote or rural location. Fan literature often defines fandom solely by behavior (e.g., creating fan art, attending events) and thereby fails to acknowledge that, for many, fandom is a personal and private experience that may involve few overt behaviors (Engle \& Kasser, 2005). However, given that many fans do engage in behaviors, they are important to consider and understand when conceptualizing ARPA.

Fantasies. Although peer interactions and other external factors play a role in adolescent romantic development, in the case of ARPA, internal factors, particularly fantasies, are especially important. We understand fantasy as a specific combination of emotions and cognitions in the service of developing an imagined narrative, which may uniquely contribute to romantic parasocial attachments. Fantasy is a major means of exploration of self and other in romance. In fact, imagination and fantasy play a strong role in all social relationships (Giles, 2002). For adolescents considering entry into the dating world, fantasy is a healthy part of development and plays a prime role in the sexual and romantic lives of adolescents (Willis, 
1972). Additionally, lack of experience with real relationships may lead to an increased need for fantasy throughout the sexual socialization process. In Moffitt's (1993) study of teen romance readers, the experiences of fantasy were "an actual source of reality and a means for them to experience through the text their expected identities as adult, woman, and lover" (p. 245).

Caughey (1984) defines fantasy as a subjective experience, separated from reality, in which one can explore the fulfillment of unconscious wishes and personal gratifications, arguing that media, particularly narrative media, are designed specifically to invoke fantasizing in viewers. Yet beyond being transported into the fantasy world of a public narrative, parasocial relationships with media figures often involve fans creating fantasies of their own in which the media figure and fan interact. In fact, the fantasized version of a media figure is potentially more salient to an adolescent than the actual version (Adams-Price \& Greene, 1990). Following object-relations theory, fanship involves attachment to internal representations, not actual people (Stever, 2009). Fantasies built on these internal representations allow viewers to develop parasocial relationships that feel intimate and accessible despite the limitations on actual access to media figures (Giles, 2002).

By imagining and fantasizing about a relationship with a media figure, adolescents can access and understand their feelings and emotions related to romance (Engle \& Kasser, 2005). Fantasy interactions are safe, secure, and controlled by the fan (Engle \& Kasser, 2005). They allow not only the fantasy of being in a relationship with a media figure but also the possibility of a fantasy self who engages in this relationship (Caughey, 1984). In these relationships, fans can be their best selves and they can project their desired qualities onto celebrities based on limited information from media sources. 
These components of ARPA, although described as theoretically distinct, are likely to be mutually constitutive, and the lines between them, while useful for building theory and systematic research, are perhaps not so clear in the lived experiences of fans.

\section{ARPAs in the Trajectory of Romantic Development}

Together, cognitions, emotions, fantasies, and behaviors provide the basis for complex, multi-dimensional romantic attachments to media figures during adolescence. These attachments provide a safe space for the exploration of identity, romance, and sexuality for young adolescents and fit well into the trajectory of adolescent development of romantic relationships proposed by B.B. Brown (1999). His model of romantic development begins with early romantic experiences providing the foundation upon which romantic scripts, schemas, and beliefs are built. However, his work does not centrally engage the possibility that mediated romantic experiences may ease the transition to adult relationships and the development of healthy self-image and identity in adolescence (Theran et al., 2010).

As depicted in Figure 3, we argue that ARPAs may join the trajectory of adolescent romantic development as an important precursor to B.B. Brown's initiation stage. Karniol (2001) proposes a model involving the evolution of media attachment objects across girls' development, beginning with initial attachments to female role model figures, shifting to attachments to feminized males in early adolescence and more masculine males later in adolescence. Work from Greene and Adams-Price (1990) and Engle and Kasser (2005) supports this pattern. Given this proposition, we propose that, for most adolescents, first ARPAs occur prior to early interpersonal romantic experiences.

[FIGURE 3 ABOUT HERE] 
Given their early emergence and documented role in script and schema development, it is likely that ARPAs play an important role in overall adolescent romantic and sexual development. In early adolescence, accumulating romantic experiences is an important task that helps build romantic identities and relationships. These experiences can impact schemas, scripts, normative beliefs, and partner preference in adolescents (Greene \& Adams-Price, 1990; Miller \& Sroufe, 1999). Romantic experiences encompass all activities and cognitions related to romantic relationships - this includes interpersonal romantic relationship experiences but also cognitive and emotional phenomena outside of these relationships such as crushes, fantasies, exposure to scripts and schemas (Collins, Welsh, \& Furman, 2009), and (we argue) ARPAs. We assert that these parasocial relationships, along with individual factors and interpersonal romantic relationships and experiences, shape adolescent romantic development and may contribute to long-term relationship satisfaction, emotional well-being, and other developmentally relevant outcomes. As illustrated by Figure 4, we propose that both ARPAs and reciprocal romantic relationships with people who are not media figures arise out of adolescents' sociocultural contexts and lived experiences (e.g. family, peers, media exposure) and may influence one another and future romantic relational outcomes.

\section{[FIGURE 4 ABOUT HERE]}

It is essential that researchers begin to study this phenomenon more seriously as ARPAs may be a moderator of media effects (Cohen \& Perse, 2003). Evidence suggests that strong parasocial attachment to media figures can influence interpretation of media narratives (Cohen, 2002), adoption of scripts, schemas and norms presented in media narratives (Rubin \& Step, 2000), changes in attitudes and behavior following exposure to media narratives (Basil, 1996; Boon \& Lomore, 2001), and idealization of future relationships (Burnett \& Beto, 2000). 
Additionally romantic parasocial relationships in adolescence could shape partner preferences or models of desired partners based on media depictions and ARPA targets (Adams-Price \& Greene, 1990; Burnett \& Beto, 2000; Lee, Fiske, Glick, \& Chen, 2010; Tukachinsky, 2010). The nature of these effects likely depends on the media contexts and objects of affection involved in ARPA relationships.

Greenwood and Long (2011) suggest that research on parasocial relationships involving romantic idealization should focus on those populations for whom these relationships are especially appealing. There is reason to believe that adolescent girls, in particular, may be uniquely susceptible to the narratives provided by romantic media figures. Considering this population, Erickson and Dal Cin (2017) found that $92 \%$ of undergraduate women reported engaging in a romantic parasocial relationship in early adolescence. Although it is likely that these attachments exist in some form for adolescent boys, they appear to be more ubiquitous and powerful for adolescent girls for a couple of reasons. First, the minimization of physical and emotional risk is likely a key motivation for engagement in ARPAs in young women (Karniol, 2001). As women are taught to be especially vigilant about these risks, celebrity relationships may be especially valuable for romantic praxis with minimal physical risk (Meier \& Allen, 2009). Second, for adolescent girls, major emphasis (and social pressure) is typically placed on the importance of being in love and having a romantic relationship (Simon et al., 1992). Adolescent girls are socialized into these relationships with media figures through norms of romantic attachment, femininity norms, and a focus on relationships in their social development (J. D. Brown et al., 1993; Ward \& Friedman, 2006).

The ARPA model was constructed to facilitate empirical examination of the ARPA experience as a normative stage of adolescent romantic development and open avenues for future 
inquiry into relationship development, parasocial relationships, and media effects. More importantly, the serious, non-pathological consideration of this phenomenon will contribute to a broader understanding of adolescent development and provide opportunities for intervention and education. In arguing for the developmental significance of early romantic relationships and experiences in adolescence, Collins (2003) identified a key question to guide future research: "How and under what conditions do romantic relationships affect individual development?" Collins (2003) went on to call for exploration of interconnections and synergisms related to social context as a fruitful area for further research. Building on Collins' suggestions, we ask the question, "How and under what circumstances do ARPAs affect individual development in conjunction with reciprocal romantic relationships?"

\section{Suggestions for ARPA Research}

More theoretical development and empirical research are needed to further define the experience of ARPA and its role in adolescent development. Specifically, it will be important to approach this topic from multiple methodological viewpoints and across populations in order to better understand what these relationships look like and how they fit into the larger process of adolescent development and the larger media environment and parasocial relationship network of adolescents.

\section{ARPA and Adolescent Development}

It is possible to imagine both adaptive and maladaptive functions of ARPA. As a normative part of adolescence, romantic parasocial attachments have the potential to positively affect development. If parasocial romantic attachments are the first step in the transition to dating, they may have similar effects on adolescents as early interpersonal romantic attachments. Positive emotions from early romantic relationships are associated with open-mindedness, 
perseverance, self-confidence, self-esteem, and social confidence (Collins et al., 2009; Larson et al., 1999). Like these early reciprocal relationships, parasocial romantic attachments likely also influence identity through the safe exploration of romantic identity and the ways in which parasocial romantic attachments and romantic socialization relate to other areas of development such as family and peer relationships and career aspirations (Collins et al., 2009).

Conversely, ARPA could be associated with maladaptive developmental outcomes. As in mutual interpersonal relationships, attributes of the romantic partner or object of affection likely influence the quality of a relationship (Collins et al., 2009). Negative emotions experienced by adolescents during romantic relationships are associated with closed-mindedness and depressive symptoms (Larson et al., 1999). Moreover, even when the emotional experience of a relationship is positive, adolescents can be blinded by love and unable to judge a situation or potential partner clearly (Larson et al., 1999). Being swept up in romance could lead to emulation or acceptance of risky or destructive behaviors (Boon \& Lomore, 2001).

The content of the media consumed in association with the parasocial romantic relationship could also have negative outcomes for adolescents. Romantic content in the media tends to focus on traditional gender roles, a common, heterosexual script, and romantic myths that reinforce an idealization and prioritization of romantic relationships over other relationships (Clasen, 2010; Florsheim, 2003). The impact of these messages is likely moderated by involvement in ARPAs (Driesmans, Vandenbosch, \& Eggermont, 2016). The drench hypothesis (Greenberg, 1988), which has received little support in studies of briefer parasocial interactions with media characters, may be redeemed in the context of ARPAs due to their sheer emotional profundity. The drench hypothesis holds that a few high-impact exposures, like those with ARPA figures, may have stronger and longer lasting effects than large quantities of general 
media exposure (Greenberg, 1988). Recurring, high impact immersion in media narratives via parasocial relationships, particularly for young women, heightens media effects (Driesmans et al., 2016). In the future, researchers will need to closely examine the nature of ARPAs, the contexts in which they occur, the adaptive and maladaptive functions they may play in adolescent development, and the way they interact with reciprocal romantic relationships in shaping emerging adults' romantic preferences and decisions.

\section{Methodological Diversity}

Empirical investigation of the theoretical model we have laid out requires a reliable and valid means of measuring these forms of attachment. A scale measuring the nature and intensity of ARPAs would allow researchers to examine how these attachments relate to other aspects of adolescent development and media effects. Such a scale should account for the cognitive, affective, behavioral, and fantasy elements of ARPA and should be applicable to both crosssectional and longitudinal research. As with much research on psychological development and media effects, the best way to measure this influence would be a longitudinal study beginning in early adolescence and running through early adulthood. A longitudinal approach would allow us to trace the romantic socialization process from first celebrity crushes to long-term committed reciprocal relationships and determine the interactive roles of interpersonal relationships, ARPA, and other contextual factors in the romantic developmental process.

Giles (2002) argues for increased attention to qualitative and ethnographic methodology in parasocial relationship research-emphasizing the importance of allowing audiences to speak to their own experiences and add depth to quantitative research findings. As such, it will also be essential to engage in further qualitative ethnographic research to elucidate the nuances in ARPA as a lived experience that cannot be easily captured in survey questions. 
A further methodological consideration for future research will be the extent to which behavior is measured or incorporated into our understanding of ARPAs. It would likely be fruitful to examine specific behaviors and the behaviors of individuals but, due to the high level of variability in behaviors, a cumulative behavioral measure may have limited validity in measuring ARPAs. For many, parasocial relationships are personal and private experiences that may involve few overt behaviors but still engage strong emotional attachments (Engle \& Kasser, 2005).

Populations of interest. There are several populations for whom ARPAs may provide an especially common or powerful means of minimizing risk in romantic socialization. Beyond heterosexual adolescent women, ARPA may play a central role in romantic relational development for LGBTQ youth. Queer adolescents face high emotional and social risks when entering romantic relationships in adolescence (Langenderfer-Magruder, Walls, Whitfield, Brown, \& Barrett, 2016). ARPAs may provide a safe space to explore sexuality and also, depending on social or geographic context, provide objects of affection when local options for exploring these early attachments are limited or prohibited. Early experimentation with celebrity attachment may be an especially attractive means of managing both physical and reputational risk for LGBTQ youth entering the worlds of dating, sex, and romance.

It will also be fruitful to examine how different social and ethnic groups engage with and are engaged by ARPAs. For example, there is evidence that media effects are moderated by racial identification of the viewer and whether the content being viewed is culturally relevant (Ward, 2004). How might the fact that the majority of media personae in the U.S. are white make the ARPA experience more or less central to the development of adolescents of color? In cultures where the norms of dating and romance differ from those of the U.S. and other 
Westernized countries, do ARPAs assume a different form or role in development? Are there cultures where ARPAs are especially prevalent or entirely absent?

\section{The Lived Experience of ARPA}

Finally, understanding how ARPAs function and what practices, beliefs, and experiences are associated with them will be important in determining their role across populations of interest. Several key questions present themselves regarding the nature of ARPA as lived experiences. It is widely recognized that social and physical attraction play a major role in catalyzing parasocial relationships in general (Rubin \& Step, 2000), but the specific developmental stage and romantic nature of ARPA experiences may relate to differences in how the relationships are initially formed and then deepened. It is also important to understand if, how, and when these relationships end and whether their nature shifts across the lifespan. How do adolescents transition to interpersonal romantic relationships from ARPAs? What is the role of these ARPAs beyond adolescence? Cohen (2003) has examined the break-up of parasocial relationships generally; understanding when and how ARPAs end (and under what circumstances they do not end) will provide insight into their necessity, and the causes of their subsequent obsolescence, in the course of adolescent development.

We also need to better understand how media figures become targets of these attachments. As Collins (2003) points out, context is central to the development of romantic relationships in adolescence, and a major source of context for relationships is the nature of the romantic partner. Individual celebrities or types of celebrities may be particularly attractive at certain moments in development (Karniol, 2001), and, attraction to these celebrities may change over time as young women mature sexually and gather reciprocal relationship experiences. Celebrities are media productions, designed to promote emotional relationships by facilitating 
viewership and loyalty (Giles, 2000; Horton \& Wohl, 1956). Additionally, the emergence of social media has changed the media context, and fundamental unidirectionality, of ARPAs.

\section{Conclusion}

ARPAs are a developmentally normative, common experience for adolescents and may play an important and even essential role in the trajectory of modern adolescent romantic and sexual development (B.B. Brown, 1999; Erickson \& Dal Cin, 2017). However, these relationships are also commercially driven and, in many ways, controlled by media industries. It is important to remember that while other socialization agents such as parents or peers generally have the adolescent's best interest at heart, media generally have financial interests that take precedence and may limit any motivation to present representations that maximize positive developmental outcomes (Arnett, 1995). Many media characters and figures targeted to young audiences are marketed as human fantasies designed to induce parasocial romance (Aubrey et al., 2010). Caughey (1984) and Horton and Wohl (1956) similarly argue that media attempt to package and manipulate the parasocial experience to capture audiences through camera angles, illusions of intimacy, and engagement of target audiences. In recent years, the power of ARPAs may be stronger than ever due to the convergence of media outlets and narratives and the presence of celebrities, both in character and as themselves, on social media sites such as Twitter, Instagram, and Facebook (Marwick \& boyd, 2011).

In her seminal work on romance readers, Radway (1991) argued for the separation of media content from media practices in audience analysis. Before we can begin to understand the role of specific media content within ARPAs, we must first understand the practices associated with the relationships, by examining their common features and exploring how they fit into adolescent development. Because media are powerful socialization agents and celebrity culture 
saturates the daily lives of adolescents, it is essential that we understand how adolescents' interactions with media figures, specifically romantic parasocial attachments, may influence adolescent development. We hope the ARPA model provides a lens through which developmentally inclined researchers can make sense of these relationships in all their complexity. 


\section{Figures}

Figure 1. Relevant Areas of Literature

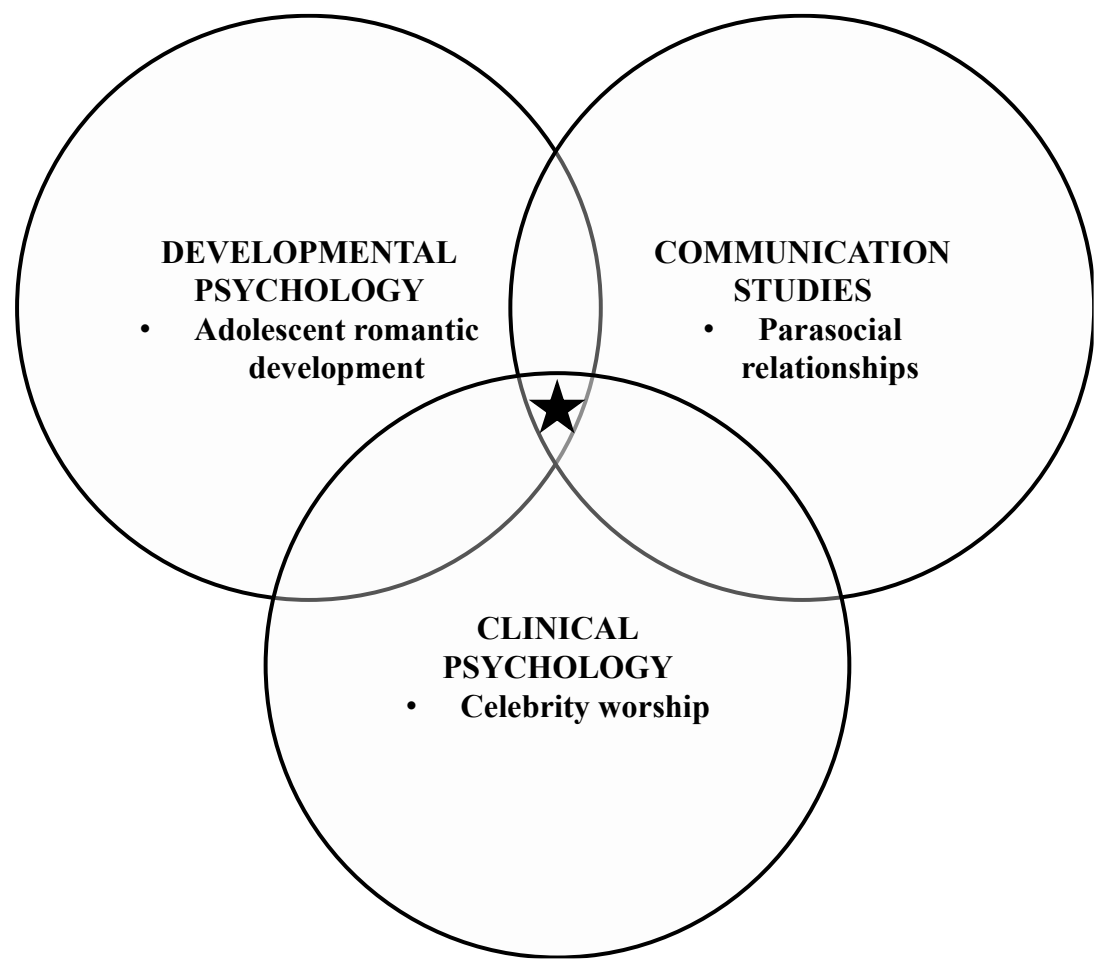


Figure 2. Components of Adolescent Romantic Parasocial Attachment.

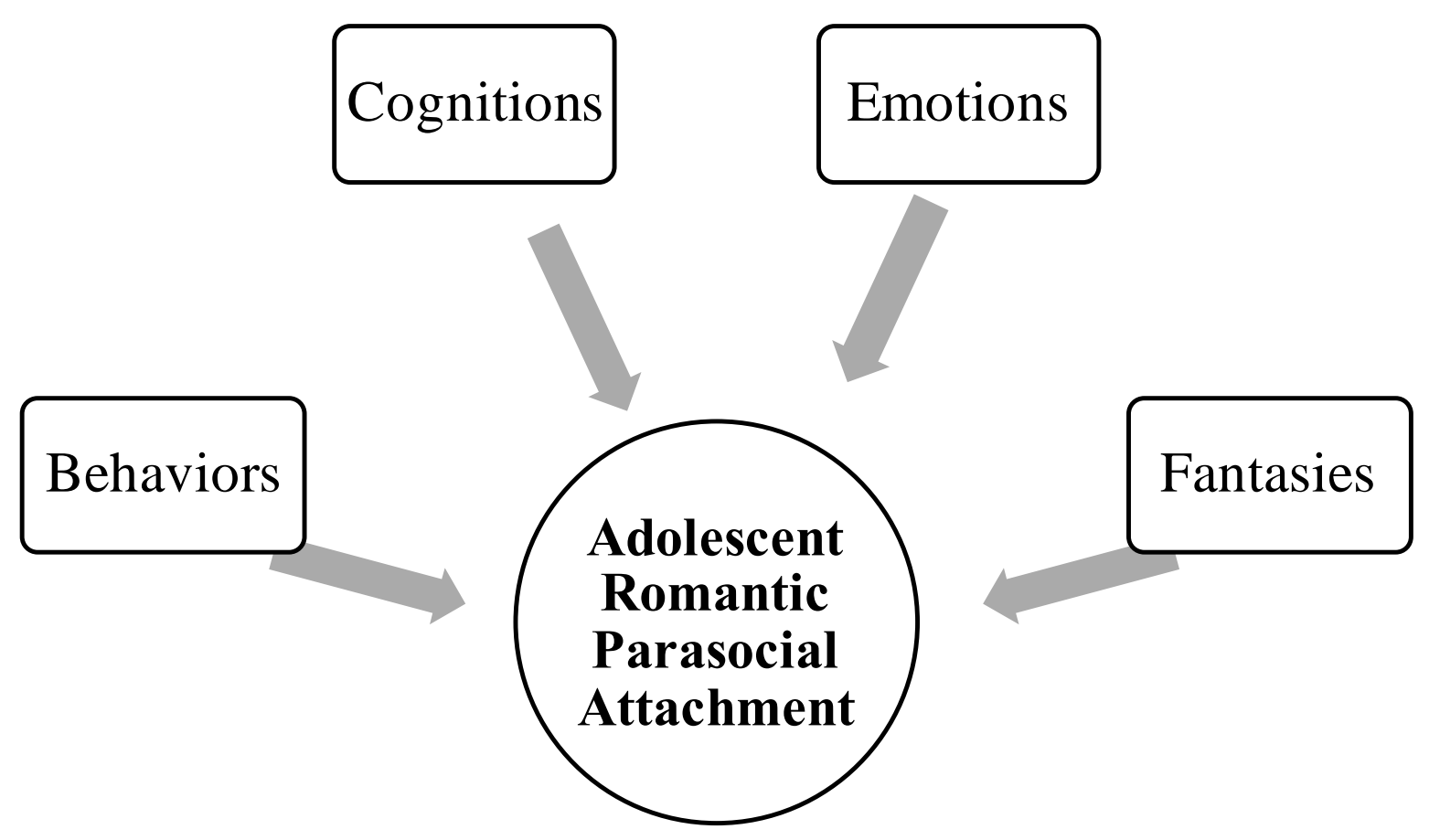


Figure 3. ARPA and the trajectory of romantic development.

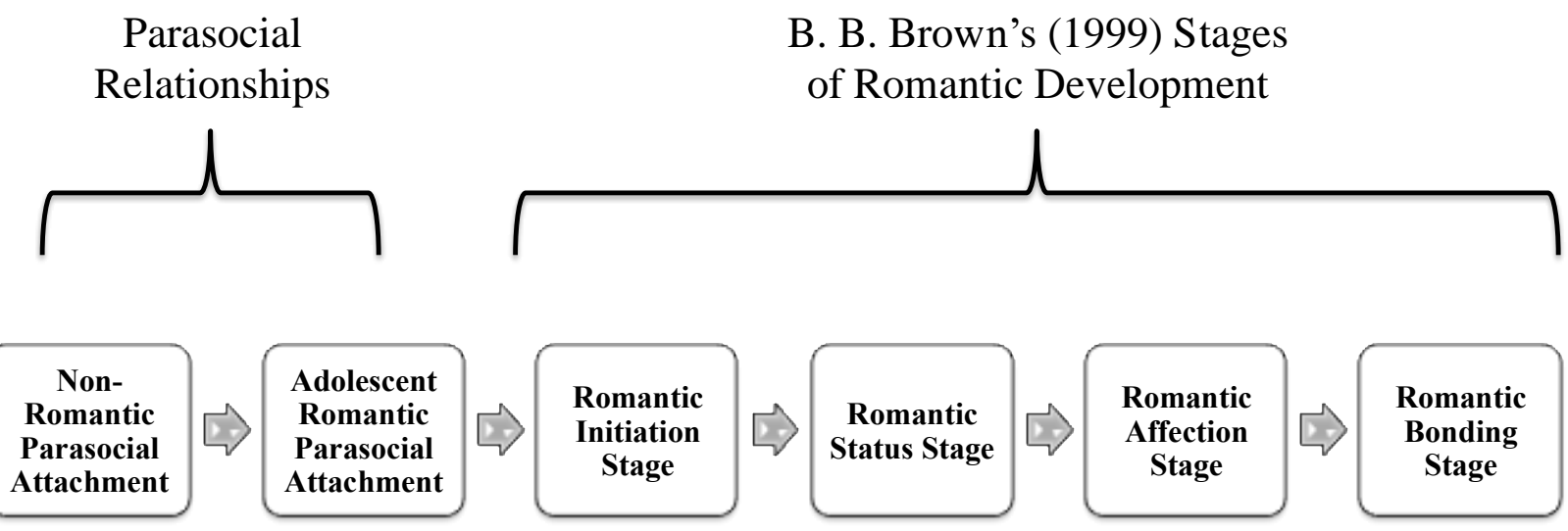

Pre-adolescent $\sum$ Early adolescent $\rangle$ Middle adolescent $\rangle$ Late adolescent $\rangle$ Emerging adult 
Figure 4. New developmental model of adolescent romantic development.

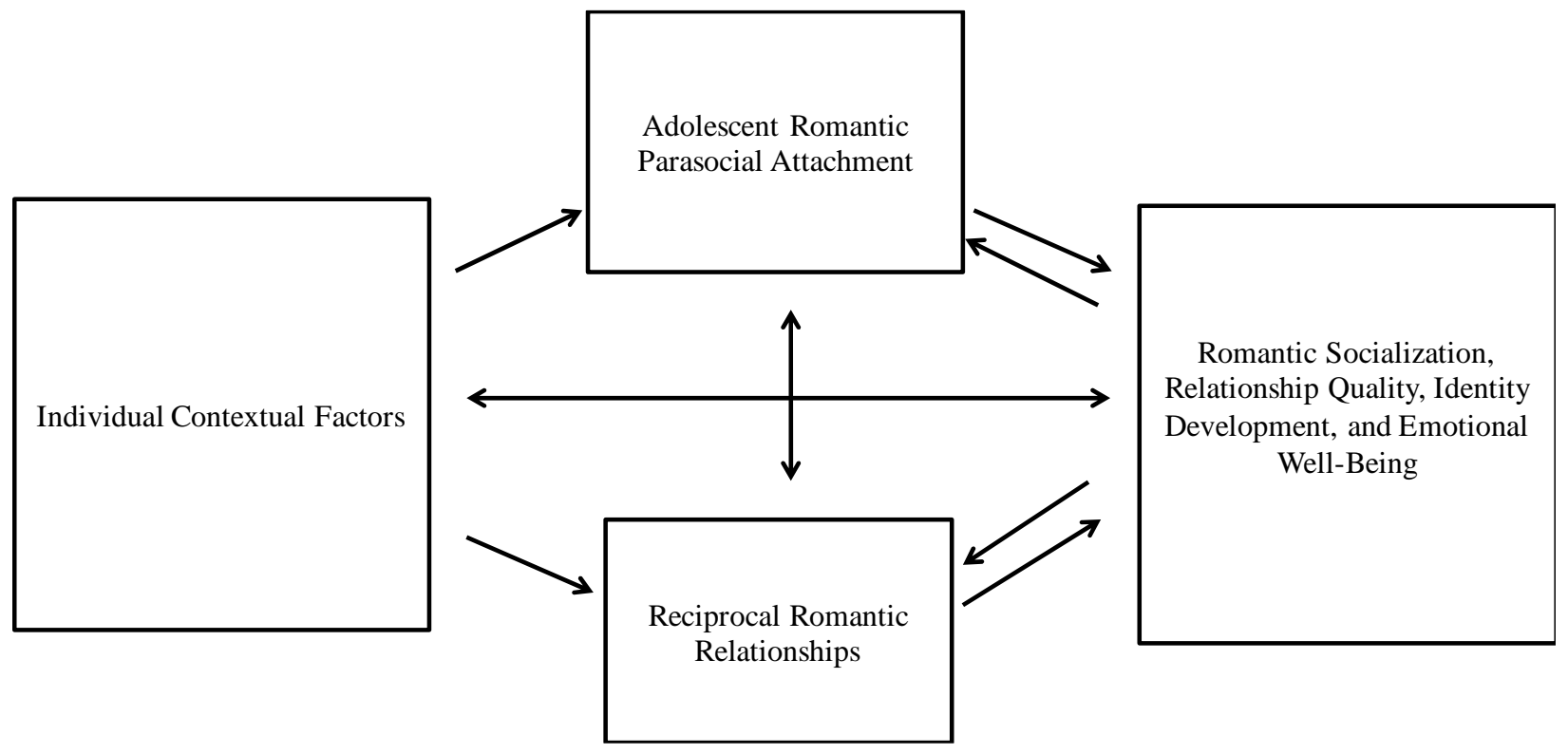




\section{References}

Adam, A. \& Sizemore, B. (2013). Parasocial romance: A social exchange perspective. Interpersona, 7(1). doi:10.5964/ijpr.v7i1.106

Adams-Price, C. \& Greene, A. L. (1990). Secondary attachments and adolescent self-concept. Sex Roles, 22(3/4), 187-198. doi: 10.1007/BF00288191

Arnett, J. J. (1995). Adolescents' uses of media for self-socialization. Journal of Youth and Adolescence, 24(5), 519-533. doi: 10.1007/BF01537054

Aubrey, J. S., Walus, S. \& Click, M. (2010). Twilight and the production of the $21^{\text {st }}$ century teen idol. In M. Click, J. S. Aubrey, and E. Behm-Morawitz (Eds.) Bitten by Twilight: Youth culture, media and the vampire franchise. New York, NY: Peter Lang Publishing.

Auter, P. \& Palmgreen, P. (2000). Development and validation of a parasocial interaction measure: The Audience-Persona Interaction Scale. Communication Research Reports, 17(1), 79-89. doi: 10.1080/08824090009388753

Basil, M. (1996). Identification as a mediator of celebrity effects. Journal of Broadcasting and Electronic Media, 40(4), 478-496. doi: 10.1080/08838159609364370

Blakemore, S-J. (2012). Imaging brain development: The adolescent brain. NeuroImage, 61, 397-406. doi: 10.1016/j.neuroimage.2011.11.080

Blankstein, U., Chen, J., Mincic, A., McGrath, P., \& Davis K. (2009). The complex minds of teenagers: Neuroanatomy of personality differs between sexes. Neuropsychologia, 47, 599-603. doi: 10.1016/j.neuropsychologia.2008.10.014

Bleakley, A., Hennessy, M., Fishbein, M., \& Jordan, A. (2008). It works both ways: The 
relationship between exposure to sexual content in the media and adolescent sexual behavior. Media Psychology, 11(4), 443-461. doi: 10.1080/15213260802491986

Boon, S. \& Lomore, C. (2001). Admirer-celebrity relationships among young adults:

Explaining perceptions of celebrity influence on identity. Human Communication Research, 27(3), 432-465. doi: 10.1111/j.1468-2958.2001.tb00788.x

Brizendine, L. (2006). The female brain. New York, NY: Three Rivers Press.

Brown, B.B. (1999). "You're going out with who?" Peer group influences on adolescent romantic relationships. In W. Furman, B.B. Brown, \& C. Feiring (Eds.) The development of romantic relationships in adolescence (pp. 291-329). Cambridge, UK: Cambridge University Press.

Brown, J., Barton White, A. \& Nikopoulou, L. (1993). Disinterest, intrigue, resistance: Early adolescent girls' use of sexual media content. In B. Greenburg, J. Brown and N. BuerkelRothfuss (Eds.) Media, sex and the adolescent. Creskill, NJ: Hampton Press.

Burnett, A. \& Beto, R.R. (2000). Reading romance novels: An application of parasocial relationship theory. North Dakota Journal of Speech and Theater, 13, 28-39.

Carver, K., Joyner, K., \& Udry, J. R. (2003). National estimates of adolescent romantic relationships. In P. Florsheim (Ed.) Adolescent romantic relations and sexual behavior: Theory, research, and practical implications (pp. 23-56). Mahwah, NJ: Lawrence Erlbaum Associates.

Caughey, J. (1984). Imaginary social worlds. Lincoln, NE: University of Nebraska Press.

Chandra, A., Martino, S., Collins, R., Elliott, M., Berry, S., Kanouse, D., \& Miu, A. (2008). Does watching sex on television predict teen pregnancy? Findings from a national longitudinal survey of youth. Pediatrics, 122 (5), 1047-1054. 
Cohen, J. (2002). Deconstructing Ally: Explaining viewers' interpretations of popular television. Media Psychology, 4, 253-277. doi: 10.1207/S1532785XMEP0403_03

Cohen, J. (2003). Parasocial breakups: Measuring individual differences in responses to the dissolution of parasocial relationships. Mass Communication and Society, 6(2), 191-202. doi: 10.1207/S15327825MCS0602_5

Cohen, J. (2004). Parasocial break-up from favorite television characters: The role of attachment styles and relationship intensity. Journal of Social and Personal Relationships, 21(2), 187-202. doi: 10.1177/0265407504041374

Cohen, J., \& Perse, E. (2003, May). Different strokes for different folks: An empirical search for different modes of viewer-character relationships. Paper presented at the International Communication Association Annual Conference, San Diego, CA.

Collins, W. A. (2003). More than myth: The developmental significance of romantic relationships during adolescence. Journal of Research on Adolescence, 13(1), 1-24. doi: $10.1111 / 1532-7795.1301001$

Collins, W. A., Welsh, D. P., \& Furman, W. (2009). Adolescent romantic relationships. Annual Review of Psychology, 60, 631-652. doi: 10.1146/annurev.psych.60.110707.163459

Driesmans, K., Vandenbosch, L., \& Eggermont, S. (2016). True love lasts forever: the influence of a popular teenage movie on Belgian girls' romantic beliefs. Journal of Children and Media, 10(3). doi: 10.1080/17482798.2016.1157501

Duffett, M. (2013). Understanding fandom. New York, NY: Bloomsbury Academic.

Engle, Y. \& Kasser, T. (2005). Why do adolescent girls idolize male celebrities? Journal of Adolescent Research, 20, 263-283. doi: 10.1177/0743558404273117

Erickson, S. E., \& Dal Cin, S. (2017) Romantic parasocial attachments and sexual socialization 
among adolescent women. Media Psychology, 1-26. doi:

$10.1080 / 15213269.2017 .1305281$

Erikson, E. (1968). Identity, youth and crisis. New York, NY: W.W. Norton and Co.

Florsheim, P. (2003). Adolescent romantic and sexual behavior: What we know and where we go from here. In P. Florsheim (Ed.) Adolescent romantic relations and sexual behavior: Theory, research, and practical implications (pp. 371-386). Mahwah, NJ: Lawrence Erlbaum Associates.

Feiring, C. (1999). Gender identity and the development of romantic relationships in adolescence. In W. Furman, B. B. Brown, \& C. Feiring (Eds.), The development of romantic relationships in adolescence (pp. 211-233). Cambridge, UK: Cambridge University Press.

Fraser, B. \& Brown, W. (2002). Media, celebrities, and social influence: Identification with Elvis Presley. Mass Communication and Society, 5(2), 183-206.

Furman, W. \& Shaffer, L. (2003). The role of romantic relationships in adolescent development. In P. Florsheim (Ed.) Adolescent romantic relations and sexual behavior: Theory, research, and practical implications (pp. 3-22). Mahwah, NJ: Lawrence Erlbaum Associates.

Furman, W. \& Simon, V. (1999). Cognitive representations of adolescent romantic relationships. In W. Furman, B. B. Brown, \& C. Feiring (Eds.) The development of romantic relationships in adolescence (pp. 75-98). Cambridge, UK: Cambridge University Press.

Galliher, R., Rostosky, S., Welsh, D. \& Kawaguchi, M. (1999). Power and psychological well- 
being in late adolescent romantic relationships. Sex Roles, 40(9/10), 689-710. doi: 10.1023/A:1018804617443

Giles, D. (2000). Illusions of immortality: A psychology of fame and celebrity. Basingstoke, UK: Palgrave Macmillan.

Giles, D. (2002). Parasocial interaction: A review of the literature and a model for future research. Media Psychology, 4, 279-305.doi: 10.1207/S1532785XMEP0403_04

Gray, M. (2009). Out in the country: Youth, media, and queer visibility in rural America. New York, NY: NYU Press.

Greenberg, B. S. (1988). Some uncommon television images and the drench hypothesis. In S. Oskamp (Ed.) Television as a social issue (pp. 88-102). Newbury Park, CA: Sage.

Greene, A.L., Adams-Price, C. (1990). Adolescents' secondary attachments to celebrity figures. Sex Roles, 23(7/8), 335-347. doi: 10.1007/BF00289224

Greenwood, D.N. \& Long, C.R. (2011). Attachment, belongingness needs, and relationship status predict imagined intimacy with media figures. Communication Research, 38 (2). doi: $10.1177 / 0093650210362687$

Horton D. \& Wohl, R. (1956). Mass communication and para-social interaction: Observations on intimacy at a distance. Psychiatry, 19(3), 215-229.doi:

$10.1080 / 00332747.1956 .11023049$

Jenkins, H. (1992). Textual poachers: Television fans and participatory cultures. New York, NY: Routledge.

Jenson, J. (1992). Fandom as pathology: The consequences of characterization. In L.A. Lewis (Ed.) The adoring audience: Fan culture and popular media (pp. 9-29). London, UK: Routledge. 
Johnson, D., Kent, A., \& E. Yale. (2012). Examination of identity and romantic relationship intimacy associations with emotional well-being in emerging adulthood. Identity: An International Journal of Theory and Research, 12, 296-319. doi:

$10.1080 / 15283488.2012 .716381$

Karniol, R. (2001). Adolescent females' idolization of male media stars as transition into sexuality. Sex Roles, 44(1/2), 61-77. doi: 10.1023/A:1011037900554

Keller, S. \& Brown, J. (2002). Media interventions to promote responsible sexual behavior. Journal of Sex Research, 39(1), 67-72. doi: 10.1080/00224490209552123

Kim, J. L., Sorsoli, C. L., Collins, K., Zylbergold, B. A., Schooler, D., \& Tolman, D. L. (2007). From sex to sexuality: Exposing the heterosexual script on primetime network television. Journal of Sex Research, 44(2), 145-157. doi: 10.1080/00224490701263660

Kirsch, A. C., \& Murnen, S. K. (2015). "Hot" girls and "cool dudes": Examining the prevalence of the heterosexual script in American children's television media. Psychology of Popular Media Culture, 4(1), 18-30. doi: 10.1037/ppm0000017

Klimmt, C., Hartmann, T. \& Schramm, H. (2006). Parasocial interactions and relationships. In J. Bryant and P. Vorderer (Eds.) Psychology of entertainment (pp. 291-313). New York, NY: Routledge.

Langenderfer-Magruder, L., Walls, N., Whitfield, D. L., Brown, S. M., \& Barrett, C. M. (2016). Partner violence victimization among lesbian, gay, bisexual, transgender, and queer youth: Associations among risk factors. Child and Adolescent Social Work Journal, 33(55), 55-68. doi: 10.1007/s10560-015-0402-8

Larson, R. W., Clore, G. L., \& Wood, G.A. (1999). The emotions of romantic relationships: 
Do they wreak havoc on adolescents? In W. Furman, B.B. Brown, \& C. Feiring (Eds.) The development of romantic relationships in adolescence (pp. 19-49). Cambridge, UK: Cambridge University Press.

Lee, T., Fiske, S., Glick, P.\& Chen, Z. (2010). Ambivalent sexism in close relationships: (Hostile) power and (benevolent) romance shape relationship ideals. Sex Roles, 62, 583601. doi: 10.1007/s11199-010-9770-X

Maccoby, E. (2007). Historical overview of socialization and research history. In J. Grusec \& P. Hastings (Eds.) Handbook of socialization, theory and research (pp. 13-41). New York, NY: Guilford Press.

Maltby, J., McCutcheon, L., Ashe, D. \& Houran, J. (2001). The self-reported psychological well-being of celebrity worshippers. North American Journal of Psychology, 3(3), 441452.

Marwick, A. \& boyd, d. (2011). To see and be seen: Celebrity practice on Twitter. Convergence, 17, 139-158. 10.1177/1354856510394539

McCutcheon, L., Ashe, D., Houran, J., \& Maltby, J. (2003). A cognitive profile of individuals who tend to worship celebrities. The Journal of Psychology, 137(4), 309-322. doi: $10.1080 / 00223980309600616$

McCutcheon, L., Lange, R., \& Houran, J. (2002). Conceptualization and measurement of celebrity worship. British Journal of Psychology, 93(1), 67-87. doi: $10.1348 / 000712602162454$

Meier, A., \& Allen, G. (2009). Romantic relationships from adolescence to young adulthood: Evidence from the National Longitudinal Study of Adolescent Health. Sociological Quarterly, 50(2), 308-335. doi: 10.1111/j.1533-8525.2009.01142.x 
Miller, B. C., \& Sroufe, L. A. (1999). Romantic and sexual relationship development during adolescence. In W. Furman, B.B. Brown, \& C. Feiring (Eds.) The development of romantic relationships in adolescence (pp. 99-123). Cambridge, UK: Cambridge University Press.

Moffitt, M. (1993). Articulating meaning: Re-conceptions of the meaning process, fantasy/reality, and identity in leisure activities. Communication Theory, 3, 354-380. doi: 10.1111/j.1468-2885.1993.tb00072.x

Owen, J., Quick, K., \& Manthos, M. (2012). I get no respect: The relationship between betrayal trauma and romantic relationship functioning. Journal of Trauma and Dissociation, 13(2), 175-189. doi: 10.1080/15299732.2012.642760

Radway, J. (1991). Reading the romance: Women, patriarchy, and popular literature, (2nd ed.). Chapel Hill, NC: University of North Carolina Press.

Rubin, A. \& Step, M. (2000). Impact of motivation, attraction and parasocial interaction on talk radio listening. Journal of Broadcasting and Electronic Media, 44(4), 635-654. doi: 10.1207/s15506878jobem4404_7

Segrin, C., \& Nabi, R. L. (2002). Does television viewing cultivate unrealistic expectations about marriage? Journal Of Communication, 52(2), 247. doi: 10.1111/j.14602466.2002.tb02543.x

Shulman, S. \& Seiffge-Krenke, I. (2001). Adolescent romance: Between experience and relationships. Journal of Adolescence, 24, 417-428. doi: 10.1006/jado.2001.0403

Simon, R., Eder, D., \& Evans, C. (1992). The development of feeling norms underlying romantic love among adolescent females. Social Psychology Quarterly, 55(1), 29-46. doi: $10.2307 / 2786684$ 
Spitzberg, B., \& Cupach, W. (2008). Fanning the flames of fandom: Celebrity worship, parasocial interaction, and stalking. In J. R. Meloy, L. Sheridan, \& J. Hoffman (Eds.), Stalking, threatening, and attacking public figures: A psychological and behavioral analysis (pp. 287-324). Oxford, UK: Oxford University Press.

Steele, J. R., \& Brown, J. D. (1995). Adolescent room culture: Studying media in the context of everyday life. Journal of Youth and Adolescence, 24(5), 551-57. doi: 10.1007/BF01537056

Steinberg, L. (2010). Adolescence, 9th Edition. New York, NY: McGraw-Hill Higher Education.

Stever, G. S. (2009). Parasocial and social interaction with celebrities: Classification of media fans. Journal of Media Psychology, 14(3), 1-39.

Stever, G. S. (2011). Celebrity worship: Critiquing a construct. Journal of Applied Social Psychology, 41(6), 1356-1370.

Stever, G.S. (2013). Mediated vs. parasocial relationships: An attachment perspective. Journal of Media Psychology, 17(3).

Taylor, L. (2015). Investigating fans of fictional texts: Fan identity salience, empathy, and transportation. Psychology of Popular Media Culture, 4(2), 162-187. doi: $10.1037 / \mathrm{ppm} 0000028$

Theran, S., Newberg, E., \& Gleason, T. (2010). Adolescent girls' parasocial interactions with media figures. The Journal of Genetic Psychology: Research and Theory on Human Development, 171(3), 270-277. doi: 10.1080/00221325.2010.483700

Tukachinsky, R. (2010). Para-romantic love and para-friendships: Development and assessment of a multiple parasocial relationships scale. American Journal of Media Psychology, 3(1/2), 73-94. 
Ward, L. M. (2002) Does television exposure affect emerging adults' attitudes and assumptions about sexual relationships? Correlational and experimental confirmation. Journal of Youth and Adolescence, 31, 1-15. doi: 10.1023/A:1014068031532

Ward, L. M. (2003) Understanding the role of entertainment media in the sexual socialization of American youth: A review of empirical research. Developmental Review, 23, 347-388. doi: 10.1016/S0273-2297(03)00013-3

Ward, L.M. (2004) Wading through stereotypes: Positive and negative associations between media use and black adolescents' conceptions of self. Developmental Psychology, 40(2), 284-294. doi: 10.1037/0012-1649.40.2.284

Willis, S. (1972) Falling in Love with Celebrities. Sexual Behavior, 2(8), 2-8. 